Original Research Paper

\title{
Cell Longevity of Yeast Saccharomyces cerevisiae by Clove Bud Extract Treatment May Occur in Sirtuin-Independent Pathway
}

\author{
${ }^{1}$ Zahrah Qolbaina Ariybah, ${ }^{1,2 *}$ Rika Indri Astuti and ${ }^{1}$ Sri Listiyowati \\ ${ }^{I}$ Department of Biology, Faculty of Mathematics and Natural Sciences, IPB University, Dramaga Campus, \\ Bogor, West Java, 16680, Indonesia \\ ${ }^{2}$ Tropical Biopharmaca Research Center, IPB University, Bogor 16128, Indonesia
}

\author{
Article history \\ Received: 21-07-2020 \\ Revised: 07-09-2020 \\ Accepted: 09-10-2020 \\ Corresponding Author: \\ Rika Indri Astuti \\ Department of Biology, \\ Faculty of Mathematics and \\ Natural Sciences, IPB \\ University, Dramaga Campus, \\ Bogor, West Java, 16680, \\ Indonesia \\ Email: rikaindriastuti@apps.ipb.ac
}

\begin{abstract}
Accumulation of free radicals causes cell damage that leads to a phenomenon called aging. Antioxidant application is one potential strategy to avoid the damage of free radical accumulation. Many reports resume that clove, one of Indonesia's spices, contain high amount of antioxidant. Our previous research had proven that clove extract could extend longevity in yeast Saccharomyces cerevisiae. However, cellular mechanism on how this extract can induce cell longevity remains unknown. One of the cellular mechanisms that involve in aging pathway is the sirtuin pathway. Therefore, this research aimed to analyze the role of sirtuin (sir2) gene in extending the life span of yeast cell. In doing so, $S$. cerevisiae sir2 gene deletion mutant $(\Delta \operatorname{sir} 2)$ was used to clarify the sir2-dependent longevity mechanism mediated by clove extract. Our data revealed that clove extract could extend yeast longevity independent to sir2 gene. In addition, clove extract could induce oxidative stress resistance phenotype of $S$. cerevisiae in sir2independent manner. Interestingly, the number of normal cell and autophagy activity also increased in $\Delta s i r 2$ mutant cells, thus suggesting autophagy may involve in prolonging longevity of $\Delta$ sir 2 mutant cells. In conclusion, clove extract could extend longevity of yeast likely via sir2independent pathway.
\end{abstract}

Keywords: Antioxidant, Longevity, Model Organism, Autophagy, $\mathrm{H}_{2} \mathrm{O}_{2}$ Scavenger

\section{Introduction}

Free radicals are unstable and harmful compound that can steal electron from other macromolecules such as lipid, protein and nucleotide in order to make itself in stable state. This compound exposure in protein and nucleotide increases susceptibility of protein to structural and functional alterations and nitrogen base damage in the DNA structure (Dizdaroglu and Jaruga, 2012). Free radicals can be produced naturally inside cell by enzymatic activity of respiration, phagocytosis and prostaglandin synthesis. Apart from enzymatic reaction in cells, free radicals also can be increased by external source such as smoke, environmental pollution, radiation, ultraviolet, ozone, several drugs, pesticides and anesthetic drug (Phaniendra et al., 2015). Free radical accumulation as cell aged leads to a phenomenon called aging. Aging caused the increasing of risk to age-related diseases such as cancer, diabetes mellitus type II, Parkinson disease, Alzheimer, heart disease and rheumatoid arthritis (Franceschi et al., 2018).

Antioxidants are potential compounds that can stabilize free radicals. This compound consists of enzymatic molecules such as catalase and superoxide dismutase. In addition, non-enzymatic compounds such as vitamin $\mathrm{C}$, flavonoids and phenolic compounds have also been reported to have antioxidant activity (Flora, 2009). Non-enzymatic compounds of antioxidant are highly produced by plants. Clove is one of Indonesian spices that contain high amount of antioxidants with eugenol as main bioactive compounds. Eugenol content in cloves varied between $9,281.60$ to $14,650.00 \mathrm{mg}$ per $100 \mathrm{~g}$ fresh weight (Neveu et al., 2010). Phenolic compound such as gallic acid, cafeic acid, ferulic acid, ellagic acid and salicylic acid also found in cloves 783.50 to $2,375.8 \mathrm{mg}$ in 100 $\mathrm{g}$ fresh weight (Shan et al., 2005). In addition, cloves 
also contain other flavonoid compounds such as caempherol, quercetin and its derivate in lower concentration. Flavonoid content of ethanol-derived extract of clove bud was reported for approximately 93.245 mg QE/100 gram (Astuti et al., 2019).

High amount of antioxidant in cloves shows that cloves are potential as an anti-aging agent. Previous research had proven that antioxidant in clove extract can extend longevity in yeast Schizasaccharomyces pombe (Fauzya et al., 2019) and Saccharomyces cerevisiae (Astuti et al., 2019). Addition of 100 and 200 ppm of ethanol-derived clove bud and leaves extract could also increase yeast survival in $\mathrm{H}_{2} \mathrm{O}_{2}$-induced oxidative stress conditions (Astuti et al., 2019; Fauzya et al., 2019). However, the mechanism of how clove extract can extend yeast longevity remains unknown.

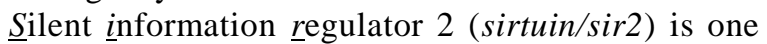
of genes that involved in $S$. cerevisiae longevity pathway. Deletion in this gene can decrease the replicative life span of $S$. cerevisiase for up to $50 \%$ (Kaeberlein et al., 1999). This gene encodes NADdependent histone deacetylase that acts in gene regulation, metabolism and NAD (H) synthesis (Ralser et al., 2012). Because of the important function of sirtuin, this gene is conserved from yeast to higher eukaryotes including mice and human. This phenomenon suggests that studying the role of sirtuin gene in extending longevity which induced by clove extract in yeast can be a reference to study the same case in higher eukaryotes. Therefore, this study was aimed to analyze the role of sirtuin gene in yeast longevity that was induced by clove bud extract.

\section{Materials and Methods}

\section{Yeast Isolates and Medium}

Yeast S. cerevisiae strain BY7471 Wild Type (WT) and Asir2 mutant (BY4741, MATa his3D1 leu2D0 met15D0 ura3D0 sir2::kanMX6) were grown in Yeast Extract Peptone Dextrose (YEPD) medium culture with $2 \%$ glucose. Hydrogen peroxide was used to induce oxidative stress environment.

\section{Extraction of Clove Bud}

The clove (Syzigium aromaticum) extract was prepared by using ethanol as described previously (Fauzya et al., 2019). The clove buds (500 grams) were macerated using $70 \%$ ethanol at a ratio of $1: 5$ (sample: Solvent) at room temperature $\left(28^{\circ} \mathrm{C}\right)$. The sample was soaked for $24 \mathrm{~h}$ and stirred at each $12 \mathrm{~h}$. Following the harvest of the macerated substance, the process was repeated twice by using the same volume of solvent. Substance was then collected and concentrated by using the rotary evaporator $\left(45^{\circ} \mathrm{C}\right)$ within one $\mathrm{h}$. The ethanol-derived extract was obtained in paste with dark brown color. The rendement of extract was $16.32 \%$ (w/w).

\section{Construction of $\Delta$ sir2 Mutant}

Gene deletion was conducted through chromosomal integration of PCR-amplified cassettes of the targeted DNA-flanking regions as described (Janke et al., 2004). The PCR cassettes for gene deletion were constructed by using template plasmid pUG6 with KanMX resistance gene $\left(K_{a n M X} \sigma^{r}\right)$ as marker. An upstream sir2 gene cassette was amplified by PCR using primer S1 (5'-GAAATGATTATTAGCAGTC3') and S2 (5'CCAGCTTTAATGTGCCGATGtgagtcttttccttaccat-

$\left.3^{\prime}\right)$ with $S$. cerevisiae genomic DNA as template, resulting 500bp amplicon. The downstream sir2 gene cassette was amplified using primer S3 (5' gctcgatgagtttttctaatGTAGAAGGCAATTTAATAAT3') and S4 (5'-ATGTGCATTGTATTACATAG-3'), with genomic DNA as template, resulting 500bp amplicon. Primer sequence with underlined indicated the sequence of $K a n M X \sigma^{r}$ gene. PCR reactions were prepared as follows: 5X PrimerSTAR buffer $\left(\mathrm{Mg}^{2+}\right.$ Plus) PCR Buffer $10 \mu \mathrm{L}$, dNTP mixture (2.5 mM each) $4 \mu \mathrm{L}$, primer forward $1 \mu \mathrm{L}(10-15 \mathrm{pmol})$, primer reverse $1 \mu \mathrm{L}$ (10-15 pmol), DNA template (genomic DNA) $0.2 \mu \mathrm{L}(150 \mathrm{ng})$, PrimeSTAR HS DNA Polymerase $0.5 \mu \mathrm{L}(1.25$ units $/ 50 \mu \mathrm{L})$ and distilled water to adjust the final volume for up to $50 \mu \mathrm{L}$. PCR was performed at the following conditions: Predenaturation $98^{\circ} \mathrm{C}, 1 \mathrm{~min}$; denaturation $98^{\circ} \mathrm{C}, 10 \mathrm{sec}$; annealing $55^{\circ} \mathrm{C}, 5 \mathrm{~min}$; polymerization $72^{\circ} \mathrm{C}, 50 \mathrm{sec}$; post PCR $4^{\circ} \mathrm{C}$. PCR was done for 30 cycles. Amplicons were then checked by using agarose gel electrophoresis and purified.

$K a n M X 6^{r}$-flanked sir2 gene domain was then constructed for each upstream and downstream region using pUG6 as template. Two sets of PCR were performed for each upstream and downstream cassette. PCR was conducted by using 500 bp upstream cassette and primer S5 (5'-ctattaatttcccetcgtca-3') as primer resulting $\mathrm{KanMX}^{r}$-flanked sir2 upstream region (1100 bp). PCR reactions $(50 \mu \mathrm{L})$ were prepared as follows: PCR Buffer $10 \mu \mathrm{L}$, dNTP mixture (2.5 mM each) $4 \mu \mathrm{L}$, primer forward $4 \mu \mathrm{L}$ (500 bp upstream cassette), primer reverse $1 \mu \mathrm{L}(10-15 \mathrm{pmol})$, DNA template (genomic DNA) $0.2 \mu \mathrm{L}$ (150 ng), Prime STAR HS DNA Polymerase $0.5 \mu \mathrm{L}(1.25$ units $/ 50 \mu \mathrm{L})$ and distilled water to adjust the final volume for up to $50 \mu \mathrm{L}$. Concurrently, KanMX $6^{r}$-flanked sir2 downstream region (1100 bp) was conducted by using 500 bp downstream cassette and primer S6 (5'-tgccaatgatgttacagatg-3'). PCR reactions $(50 \mu \mathrm{L})$ were prepared as follows : PCR Buffer $10 \mu \mathrm{L}$, dNTP mixture $(2.5 \mathrm{mM}$ each) $4 \mu \mathrm{L}$, primer forward $1 \mu \mathrm{L}$ (10-15 pmol), primer reverse $4 \mu \mathrm{L}$ (500 bp downstream 
cassete), DNA template (genomic DNA) $0.2 \mu \mathrm{L}(150$ ng), PrimeSTAR HS DNA Polymerase $0.5 \mu \mathrm{L}(1.25$ units $/ 50 \mu \mathrm{L}$ ) and distilled water to adjust the final volume for up to $50 \mu \mathrm{L}$. PCR was performed at the following conditions : Pre-denaturation $98^{\circ} \mathrm{C}, 1 \mathrm{~min}$; denaturation $98^{\circ} \mathrm{C}, 10 \mathrm{sec}$; annealing $55^{\circ} \mathrm{C}, 5 \mathrm{~min}$; polymerization $72^{\circ} \mathrm{C}, 50 \mathrm{sec}$; post PCR $4^{\circ} \mathrm{C}$. PCR was done for 30 cycles. Amplicons were then checked by using agarose gel electrophoresis and purified.

The resulted two amplicon cassettes were then introduced to yeast $S$. cerevsiae. A simple yeast transformation procedure was then performed to introduce the corresponding PCR cassettes in to $S$. cerevisiae BY4171 (Gietz and Schiestl, 2007). For selective growth of cell transformants, $100 \mu \mathrm{g} / \mathrm{mL}$ geneticin was added to YPDA medium. Transformant candidates were checked via colony PCR analysis.

\section{Viability Assay}

Spot test was used in order to analyze yeast viability following clove extract treatment within stationary phase, which correlates, to that yeast chronological life span (Fauzya et al., 2019). For sub-culture, both yeast strains (WT and $\Delta$ sir2 mutant) were grown in YEPD broth medium for $18-24 \mathrm{~h}$ at $30^{\circ} \mathrm{C}$. For main culture, yeast sub-culture was transferred in YEPD broth medium containing various concentrations of clove extract $(0,100,200 \mathrm{ppm})$ at starting OD600 $=0.1$. Main cultures were then incubated for 6 days. Main cultures were then addressed for spot assay at day 3 and 6 . Cultures were harvested and serially diluted up to $10^{4}$. About $2 \mu \mathrm{L}$ of each dilution were spotted in YEPD agar plates. Spot test results were analyzed after 3 days incubation at $30^{\circ} \mathrm{C}$.

\section{Oxidative Stress - Resistance Assay}

The assay was conducted using spot test assay as described previously (Astuti et al., 2019). Cultures were prepared as above mentioned in the viability assay. Spot was done in YEPD agar medium containing $\mathrm{H}_{2} \mathrm{O}_{2}$ in various concentrations $(2,4$ and $6 \mathrm{mM})$. Yeast viability was observed after three days of incubation at $30^{\circ} \mathrm{C}$.

\section{Yeast Morphological Assay}

Yeast cells (WT and $\Delta \operatorname{sir} 2$ mutant) were cultured in YEPD broth medium containing various concentration of clove extract $(0,100$ and $200 \mathrm{ppm})$. At day-3 of incubation, high concentration of $\mathrm{H}_{2} \mathrm{O}_{2}(2$ and $4 \mathrm{~mm})$ was then applied in culture to induce oxidative stress condition. Morphology of yeast cells was observed under light microscope in order to determine the presence of autophagic body (Tallóczy et al., 2002). To enumerate the number of autophagic bodies, about 200 cell profiles containing the vacuole were screened. Profiles containing one or more autophagic bodies inside the vacuole were classified as positive (Tallóczy et al., 2002).

\section{Results and Discussion}

\section{Clove Extract Promotes Yeast Life Span Both in Wild Type and $\Delta$ sir2 Mutant Cells.}

Cell viability assay showed that the addition of clove extract could promote the viability both WT and $\Delta s i r 2$ cells in the stationary phase both in 3 and 6 days of incubation. In 6 days of incubation, the $\Delta \operatorname{sir} 2$ cells showed slight decrease in the cells viability compared to WT cells, in non-treated cells (Fig. 1). Such phenotype is in agreement with previous study indicating that deletion of Sir 2 resulted in decrease lifespan of S. cerevisiae (Smith Jr. et al., 2007). Interestingly, addition of clove extract (100 and $200 \mathrm{ppm}$ ) could promote $\Delta s i r 2$ cells viability (Fig. 1). This data suggests that $\operatorname{sir} 2$ is unlikely to involve in the cells viability of yeast cells in stationary phase following clove extract treatment.

Sirtuin has been known as conserved key modulator of aging in eukaryotes (Grabowska et al., 2017). Sir2 in yeast is highly homolog to that SIRT1 in mammalian cells (Frye, 2006). Activation of Sir2 is reported to extend life span of model yeast S. cerevisiae (Lin et al., 2002; Wierman and Smith, 2014). Previous studies reported that sir2 gene could be activated by exogenous treatment of phytoextract primarily those containing phenolic or flavonoid compounds, such as resveratrol (Howitz et al., 2003). Sirtuin activation by butein, fisetin and resveratrol increased lifespan by 31,55 and $70 \%$, respectively (Howitz et al., 2003). Furthermore, extract of lemon beebrush and lycopene of tomato could activate SIRT1 activity in the rabbit's heart and liver tissues (Corbi et al., 2018). On the contrary, our data indicates that sirtuin may not be involved in maintaining yeast cells viability of $\Delta \operatorname{sir} 2$ cells at the stationary phase. Thus suggesting that clove extract may modulate other pathway in promoting yeast life span. Pathway relevant for aging in yeast involves nutrient signaling via key gene TORC1 (target of rapamycin complex 1) and PKA (protein kinase A) (Wei et al., 2008; Deprez et al., 2018), cell cycle regulation, DNA repair mechanisms, autophagy, mitochondrial homeostasis, lipostasis, protein folding and secretion, proteostasis, stress response and regulated cell death (Zimmermann et al., 2018). Those mechanisms are conserved in humans as well. Thus, we further analyze the potential activity of clove extract in modulating other aging pathways of sirtuin, including the induction of oxidative stress response and autophagy. 


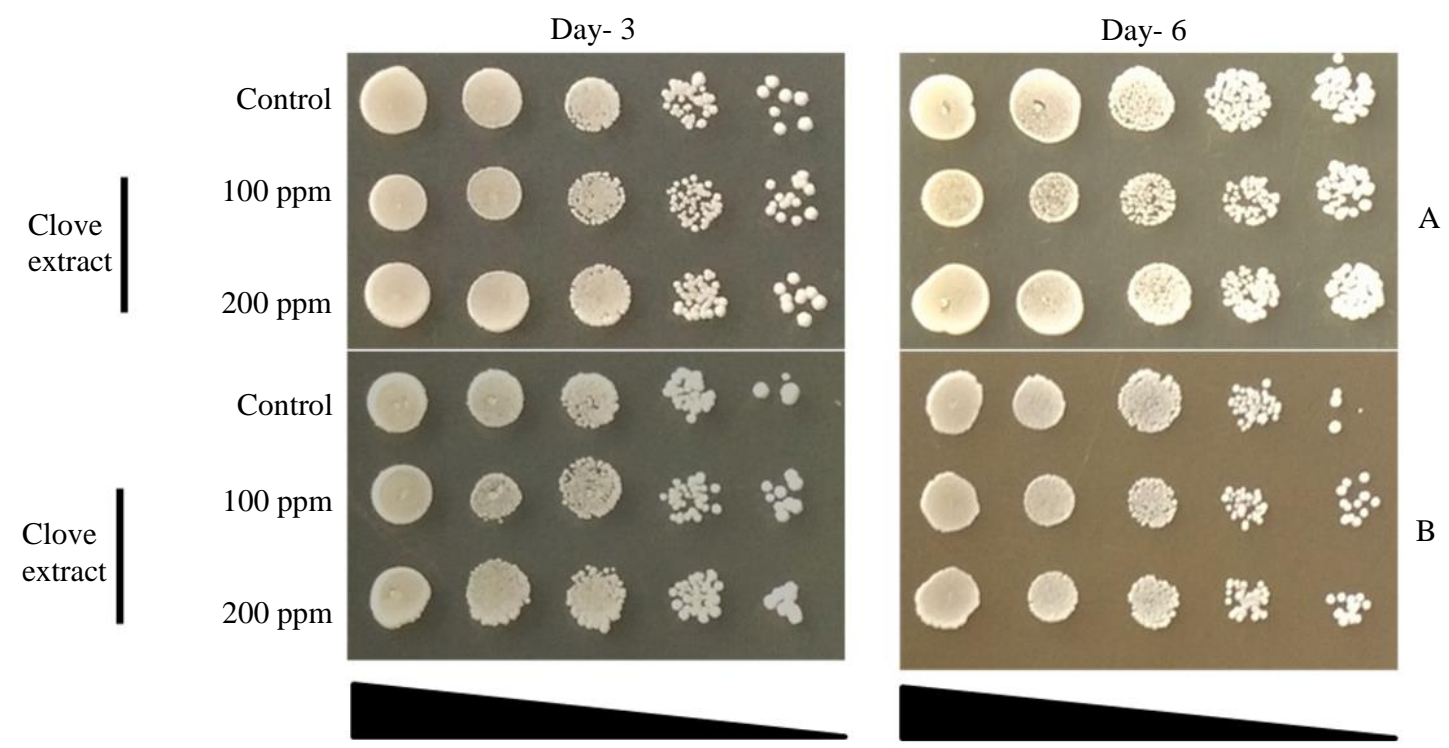

Fig. 1: Effect of clove extract treatment on the cell viability of stationary phase yeast cells of (A) S. cerevisiae WT BY4741 and (B) S. cerevisiae $\Delta$ sir2. Both WT and 4 sir2 were grown in YEPD broth medium containing various concentration of clove extract (100 and $200 \mathrm{ppm}$ ) and incubated at 300C for six days. The 3 and 6-days culture were spoted in YEPD agar plates and were incubated at 300C for three days. Yeast grown in YEPD medium without clove extract was designated as control

Clove Extract Promotes Yeast Life Span Both in Wild Type and $\Delta$ sir2 Mutant Cells Under Oxidative Stress Conditions.

$\Delta$ sir2 mutant was less resistant to $\mathrm{H}_{2} \mathrm{O}_{2}$ stress than WT cells (Fig. 2). Clove extract was shown to increase the tolerance phenotype of $\Delta$ sir 2 mutant cells against $4 \mathrm{mM}$ $\mathrm{H}_{2} \mathrm{O}_{2}$ treatment (Fig. 2). Such phenotype was also seen in WT cells particularly following $200 \mathrm{ppm}$ treatment compared to that without extract and $100 \mathrm{ppm}$ treatment. Interestingly, supplementation of $200 \mathrm{ppm}$ clove extract caused cell death phenotype of WT cells following severe oxidative stress treatment $(6 \mathrm{~mm})$, opposite to that $\Delta$ sir2 mutant cells (Fig. 2). These data suggest that sir2 is not involved in modulating stress tolerance phenotype of yeast cells following clove extract treatment. It is reported that sirtuin plays critical role in anti-oxidant protective response in mammalian cells (Merksamer et al., 2013). However, our data indicates that addition of clove extract could diminish the negative effect of sir2 gene abrogation in yeast cells.

Oxidative stress is one of the causal factors of cellular aging. Thus, antioxidant compound, such as flavonoids and phenolics compounds that could combat the oxidative stress may potentially be applied as antiaging agent. Previous studies exhibit anti-aging properties of clove extract (Astuti et al., 2019), roselle petal extract (Sarima and Meryandini, 2019), hesperidin-derived from Citrus genus (Sun et al., 2012) as antiaging agent in yeast S. cerevisiae due to its high antioxidant activity. Oxidative stress response pathway might be one of the targets of action of the antioxidant compounds at cellular and molecular levels. Such compounds may induce genes that involve in oxidative stress response pathway thus inducing the stress tolerance phenotype (Maeta et al., 2007). It is worth noting that clove has been reported to have flavonols compounds such as quercetin $(28.40 \mathrm{mg} / 100$ gram) and kaempferol (23.80 mg/100 gram) (Shan et al., 2005). Previous studies showed that quercetin exhibits a protective effect in $S$. cerevisiae against oxidative stress via induction of trehalose biosynthesis (Vilaça et al., 2012), attenuation of lipid peroxidation and protein carbonylation (Belinha et al., 2007). Thus, further study is required to gain more insight in the clove extract-dependent oxidative stress tolerance mechanism in yeast, since clove contains other bioactive compounds including phenolic compounds in which gallic acid is found in high levels (458.19 mg/100 g FW). Interestingly, gallic acid, has been reported to have antiaging activity toward yeast $S$. cerevisiae (Đorđević et al., 2018). However, cellular mechanism of gallic acid in extending yeast life span remains unclear.

\section{Clove Extract Increases Autophagy Activity}

Autophagy has been implicated as one of the regulatory mechanism in prolonging yeast life span (Howitz et al., 2003; Borklu-Yucel et al., 2015). Our data indicate that clove extract treatment increased autophagic body of WT cells in both normal and oxidative stress conditions (Fig. 3). 


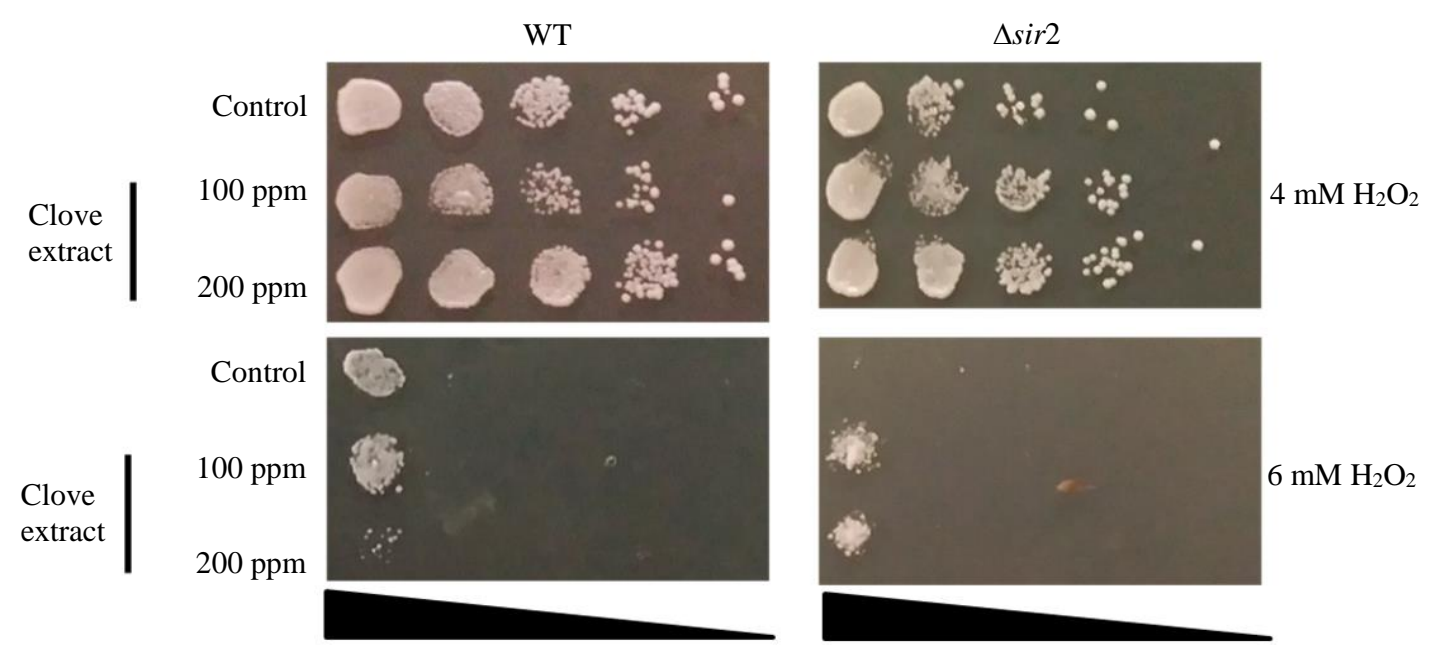

Fig. 2: Effect of clove extract supplementation on yeast viability of both $S$. cerevisiae WT and mutant $\Delta$ sir2 in combating 4 and $6 \mathrm{mM} \mathrm{H}_{2} \mathrm{O}_{2}-$ induced oxidative stress treatment. Yeast grown without clove extract addition was used as control. Yeast cells were grown in YES medium containing 100 or $200 \mathrm{ppm}$ clove extract and incubated for 3 days at $30^{\circ} \mathrm{C}$. Culture was then spotted in YES-agar medium containing high concentration of $\mathrm{H}_{2} \mathrm{O}_{2}(2$ and $4 \mathrm{~mm})$. Yeast grown without clove extract addition was designated as control

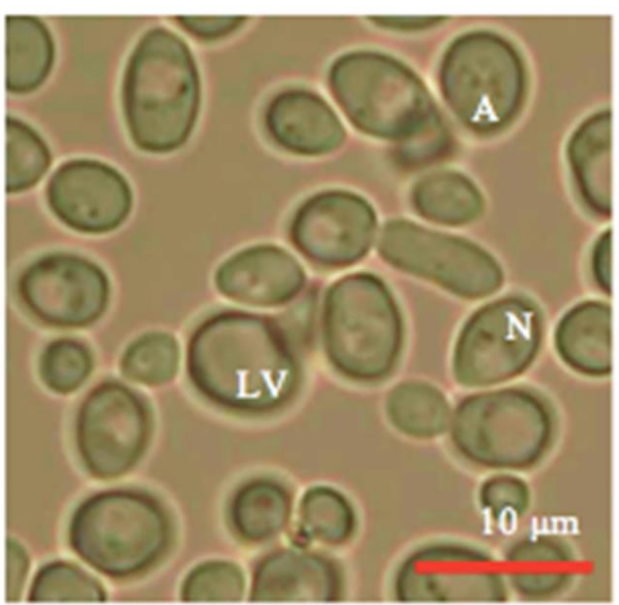

(A)
A: Autophagic body

$\mathrm{N}$ : Normal Cell

LV: Large Vacuole cell

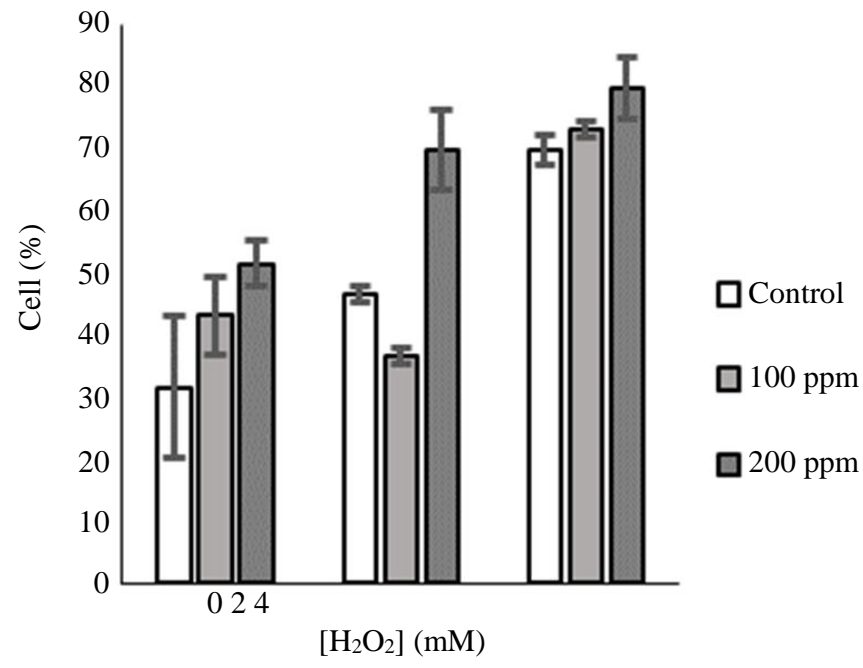

(B) 


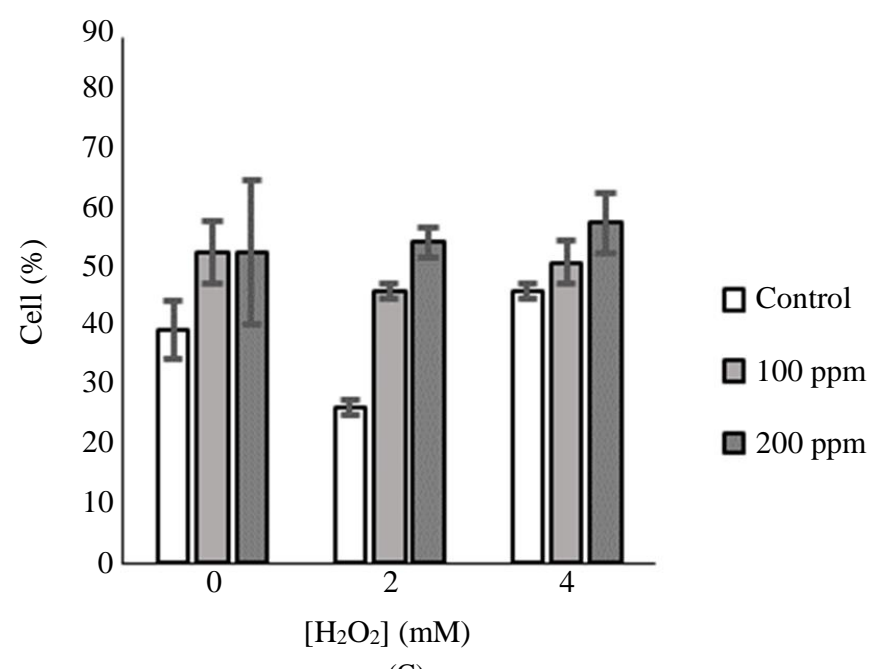

(C)

Fig. 3: Effect of clove extract on the autophagic bodies formation (A) in (B) S. cerevisiae WT and (C) S. cerevisiae $\Delta$ sir2 in various hydrogen peroxide treatment. Yeast cells were grown in YES medium containing 100 or 200 ppm clove extract and incubated for 6 days at $30^{\circ} \mathrm{C}$. At day-3 of incubation, high concentration of $\mathrm{H}_{2} \mathrm{O}_{2}(2$ and $4 \mathrm{mM})$ was then applied in culture to induce oxidative stress condition. Yeast grown without clove extract addition was used as control

Following $200 \mathrm{~mm}$ clove extract, the number of autophagic bodies in $S$. cerevisiae and 4 sir2 mutant, under $2 \mathrm{~mm} \mathrm{H}_{2} \mathrm{O}_{2}$-induced oxidative stress conditions, was increased for 49.9 and $105.9 \%$, respectively. The number of autophagic body in 4 sir2 mutant was significantly lower than WT cells. Thus, indicating that sir2 gene is involved in the autophagy activity (Fig. 3B). This data is consistent with previous study which revealed that during chronological aging, Sir2 activates autophagy (Lee et al., 2019). Sir2 activation is also reported to occur as an intersection between nutrient and energysensing pathways, mediated by target of rapamycin (TOR)/S6 kinase homolog Sch9 through effects on autophagy (Tyler and Johnson, 2018). It is worth noting that, in WT strain, the number of autophagy body in $100 \mathrm{ppm}$ clove extract treatment was found lower than that of $200 \mathrm{ppm}$ extract treatment. We suggest that 100 ppm clove extract is the optimum concentration of clove extract that elicits rapid changes in the oxidative stress- response in WT yeast. Thus at 6 days of incubations, we found that the autophagy body of WT treated with $100 \mathrm{ppm}$ clove extract was relatively similar to that without $\mathrm{H}_{2} \mathrm{O}_{2}$ treatment. This particular condition is considered as the WT cells were no longer experiencing stress conditions (normal conditions). However, further study is needed to clarify these dynamic intracellular conditions.

Based on the potential increasing pattern of autophagy in WT strain in without oxidative stress conditions, we suggest that sir2 may involve in the regulation of autophagy body via clove extract treatment. Thus the loss of sir2 gene resulted in the similar number of autophagy body. Interestingly, in oxidative stress conditions, our data shows that treatment of clove extract could induce the development of autophagic body in both WT and $\Delta s i r 2$ mutant. These data indicate that clove extract likely involve in inducing autophagic body independent to that sirtuin activity.

Induction of oxidative stress tolerance and autophagic body phenotype in $\Delta s i r 2$ mutant following clove extract treatment showed that the particular extract may likely act as direct scavenger of ROS-derived $\mathrm{H}_{2} \mathrm{O}_{2}$ which in turn lowers intracellular ROS level thus avoiding the development of severe oxidative stress conditions. Previous data revealed that clove oil $(22.9 \pm 2.3 \%)$ indeed had similar $\mathrm{H}_{2} \mathrm{O}_{2}$ scavenging activity to trolox (25.6 $\pm 3.3 \%)$ (Gülçin et al., 2012). In addition, clove extract have also been reported to have high metal chelating activity and Ferric Reducing/Antioxidant Power (FRAP) (Yadav and Bhatnagar, 2007). Thus, it is likely that clove extract may function as direct radical scavenger resulting in decreasing intracelluar level of ROS against $\mathrm{H}_{2} \mathrm{O}_{2}$-induced oxidative stress conditions. However, as longevity is apparently occured in multiple pathways, thus it is worth to further analyze the target of action of clove extract in prolonging yeast life span. Furthermore, the use of pure antioxidant compound from clove extract may give essential information regarding the modulatory effect of the particular compound toward aging-related cellular and molecular pathways in yeast. 


\section{Conclusion}

To our knowledge, this is the first report of confirming the effect of clove extract at cellular level by using yeast as model organism. In addition, it is likely that clove extract may prolong yeast life span and induce oxidative stress tolerance phenotype in Sir2-independent pathway. Further analysis in revealing the mode of action of clove extract is needed to clarify the pharmacological effect or possible negative-side effects of this widely consumed spice, particularly at cellular and molecular levels.

\section{Funding Information}

The authors would like to thank the Ministry of Research and Higher Education of Republic of Indonesia/BRIN for the financial support of the project to RIA for fiscal year 2021 for Basic Research Scheme.

\section{Author's Contributions}

Zahrah Qolbaina Ariybah: Has contributed in whole laboratory experiments, data analysis, paper writing.

Rika Indri Astuti: Research coordinator, handled data analysis and paper writing and revision.

Sri Listiyowati: Has reviewed and revised the manuscript.

\section{Ethics}

The authors declare that there are no conflicts of interest regarding this paper publication.

\section{References}

Astuti, R. I., Listyowati, S., \& Wahyuni, W. T. (2019, July). Life span extension of model yeast Saccharomyces cerevisiae upon ethanol derivedclover bud extract treatment. In IOP Conference Series: Earth and Environmental Science (Vol. 299, No. 1, p. 012059). IOP Publishing. https://doi.org/10.1088/1755-1315/299/1/012059

Belinha, I., Amorim, M. A., Rodrigues, P., de Freitas, V., Moradas-Ferreira, P., Mateus, N., \& Costa, V. (2007). Quercetin increases oxidative stress resistance and longevity in Saccharomyces cerevisiae. Journal of Agricultural and Food Chemistry, 55(6), 2446-2451. https://doi.org/10.1021/jf063302e

Borklu-Yucel, E., Eraslan, S., \& Ulgen, K. O. (2015). Transcriptional remodeling in response to transfer upon carbon-limited or metformin-supplemented media in S. cerevisiae and its effect on chronological life span. Applied Microbiology and Biotechnology, 99(16), 6775-6789. https://doi.org/10.1007/s00253015-6728-5
Corbi, G., Conti, V., Komici, K., Manzo, V., Filippelli, A., Palazzo, M., ... \& Ferrara, N. (2018). Phenolic plant extracts induce Sirt1 activity and increase antioxidant levels in the rabbit's heart and liver. Oxidative Medicine and Cellular Longevity, 2018. https://doi.org/10.1155/2018/2731289

Deprez, M. A., Eskes, E., Winderickx, J., \& Wilms, T. (2018). The TORC1-Sch9 pathway as a crucial mediator of chronological lifespan in the yeast Saccharomyces cerevisiae. FEMS yeast research, 18(5), foy048. https://doi.org/10.1093/femsyr/foy048

Dizdaroglu, M., \& Jaruga, P. (2012). Mechanisms of free radical-induced damage to DNA. Free radical Research, 46(4), 382-419. https://doi.org/10.3109/10715762.2011.653969

Đorđević, N. O., Todorović, N., Novaković, I. T., Pezo, L. L., Pejin, B., Maraš, V., ... \& Pajović, S. B. (2018). Antioxidant activity of selected polyphenolics in yeast cells: The case study of Montenegrin Merlot wine. Molecules, 23(8), 1971.

Fauzya, A. F., Astuti, R. I., \& Mubarik, N. R. (2019). Effect of Ethanol-Derived Clove Leaf Extract on the Oxidative Stress Response in Yeast Schizosaccharomyces pombe. International Journal of Microbiology, 2019. https://doi.org/10.1155/2019/2145378

Flora, S. J. (2009). Structural, chemical and biological aspects of antioxidants for strategies against metal and metalloid exposure. Oxidative medicine and cellular longevity, 2. https://doi.org/10.4161/oxim.2.4.9112

Franceschi, C., Garagnani, P., Morsiani, C., Conte, M., Santoro, A., Grignolio, A., ... \& Salvioli, S. (2018). The continuum of aging and age-related diseases: common mechanisms but different rates. Frontiers in medicine, 5, 61. https://doi.org/10.3389/fmed.2018.00061

Frye, R. A. (2006). Evolution of sirtuins from archaea to vertebrates. In Histone Deacetylases (pp. 183-202). Humana Press. https://doi.org/10.1385/1-59745-0243:183

Gietz, R. D., \& Schiestl, R. H. (2007). High-efficiency yeast transformation using the $\mathrm{LiAc} / \mathrm{SS}$ carrier DNA/PEG method. Nature protocols, 2(1), 31-34. https://doi.org/10.1038/nprot.2007.15

Grabowska, W., Sikora, E., \& Bielak-Zmijewska, A. (2017). Sirtuins, a promising target in slowing down the ageing process. Biogerontology, 18(4), 447-476. https://doi.org/10.1007/s10522-017-9685-9

Gülçin, İ., Elmastaş, M., \& Aboul-Enein, H. Y. (2012). Antioxidant activity of clove oil-A powerful antioxidant source. Arabian Journal of Chemistry, 5(4), 489-499. https://doi.org/10.1016/j.arabjc.2010.09.016

Howitz, K. T., Bitterman, K. J., Cohen, H. Y., Lamming, D. W., Lavu, S., Wood, J. G., ... \& Scherer, B. (2003). Small molecule activators of sirtuins extend Saccharomyces cerevisiae lifespan. Nature, 425(6954), 191-196. https://doi.org/10.1038/nature01960 
Janke, C., Magiera, M. M., Rathfelder, N., Taxis, C., Reber, S., Maekawa, H., ... \& Knop, M. (2004). A versatile toolbox for PCR-based tagging of yeast genes: New fluorescent proteins, more markers and promoter substitution cassettes. Yeast, 21(11), 947-962. https://doi.org/10.1002/yea.1142

Kaeberlein, M., McVey, M., \& Guarente, L. (1999). The $S I R 2 / 3 / 4$ complex and SIR2 alone promote longevity in Saccharomyces cerevisiae by two different mechanisms. Genes and Development, 13(19), 2570-2580. https://doi.org/10.1101/gad.13.19.2570

Lee, I. H., Mechanisms and disease implications of sirtuin-mediated autophagic regulation. Experimental and Molecular Medicine 51, 1-11 (2019). 51, 1-11. https://doi.org/10.1038/s12276019-0268-5

Lin, S. J., Kaeberlein, M. Andalis, A. A., Sturtz, L. A., Defossez, P. A., Culotta, V. C., ... \& Guarente, L. (2002). Calorie restriction extends Saccharomyces cerevisiae lifespan by increasing respiration. Nature, 418(6895), 344-348. https://doi.org/10.1038/nature00829

Maeta, K., Nomura, W., Takatsume, Y., Izawa, S., \& Inoue, Y. (2007). Green tea polyphenols function as prooxidants to activate oxidative-stress-responsive transcription factors in yeasts. Applied and Environmental Microbiology, 73(2), 572-580. https://doi.org/10.1128/AEM.01963-06

Merksamer, P. I., Liu, Y., He, W., Hirschey, M. D., Chen, D., \& Verdin, E. (2013). The sirtuins, oxidative stress and aging: An emerging link. Aging (Albany NY), 5(3), 144. https://doi.org/10.18632/aging.100544

Neveu, V., Perez-Jiménez, J., Vos, F., Crespy, V., du Chaffaut, L., Mennen, L., ... \& Scalbert, A. (2010). Phenol-Explorer: An online comprehensive database on polyphenol contents in foods. Database, 2010. https://doi.org/10.1093/database/bap024

Phaniendra, A., Jestadi, D. B., \& Periyasamy, L. (2015). Free radicals: properties, sources, targets and their implication in various diseases. Indian journal of clinical biochemistry. IJCB, 30(1), 11-26. https://doi.org/10.1007/s12291-014-0446-0

Ralser, M., Michel, S., \& Breitenbach, M. (2012). Sirtuins as regulators of the yeast metabolic network. Frontiers in Pharmacology, 3, 32. https://doi.org/10.3389/fphar.2012.00032

Sarima, A. R., \& Meryandini, A. (2019). Modulation of aging in yeast Saccharomyces cerevisiae by roselle petal extract (Hibiscus sabdariffa L.). American Journal of Biochemistry and Biotechnology, 15(1), 23-32. https://doi.org/10.3844/ajbbsp.2019.23.32
Shan, B., Cai, Y. Z., Sun, M., \& Corke, H. (2005). Antioxidant capacity of 26 spice extracts and characterization of their phenolic constituents. Journal of Agricultural and Food Chemistry, 53(20), 7749-7759. https://doi.org/10.1021/jf051513y

Smith, Jr., D. L., McClure, J. M., Matecic, M., \& Smith, J. S. (2007). Calorie restriction extends the chronological lifespan of Saccharomyces cerevisiae independently of the Sirtuins. Aging cell, 6(5), 649-662. https://doi.org/10.1111/j.1474-9726.2007.00326.x

Sun, K., Xiang, L., Ishihara, S., Matsuura, A., Sakagami, Y., \& Qi, J. (2012). Anti-aging effects of hesperidin on Saccharomyces cerevisiae via inhibition of reactive oxygen species and UTH1 gene expression. Bioscience, Biotechnology and Biochemistry, 1202232809-1202232809. https://doi.org/10.1271/bbb.110535

Tallóczy, Z., Jiang, W., Virgin, H. W., Leib, D. A., Scheuner, D., Kaufman, R. J., ... \& Levine, B. (2002). Regulation of starvation-and virus-induced autophagy by the eIF $2 \alpha$ kinase signaling pathway. Proceedings of the National Academy of Sciences, 99(1), 190-195. https://doi.org/10.1073/pnas.012485299

Tyler, J. K., \& Johnson, J. E. (2018). The role of autophagy in the regulation of yeast life span. Annals of the New York Academy of Sciences, 1418(1), 31. https://doi.org/10.1111/nyas.13549

Vilaça, R., Mendes, V., Mendes, M. V., Carreto, L., Amorim, M. A., De Freitas, V., ... \& Costa, V. (2012). Quercetin protects Saccharomyces cerevisiae against oxidative stress by inducing trehalose biosynthesis and the cell wall integrity pathway. PloS One, 7(9), e45494. https://doi.org/10.1371/journal.pone.0045494

Wei, M., Fabrizio, P., Hu, J., Ge, H., Cheng, C., Li, L., \& Longo, V. D. (2008). Life span extension by calorie restriction depends on Rim15 and transcription factors downstream of Ras/PKA, Tor and Sch9. PLoS Genet, 4(1), e13. https://doi.org/10.1371/journal.pgen.0040013

Wierman, M. B., \& Smith, J. S. (2014). Yeast sirtuins and the regulation of aging. FEMS Yeast Research, 14(1), 73-88. https://doi.org/10.1111/1567-1364.12115

Yadav, A. S., \& Bhatnagar, D. (2007). Free radical scavenging activity, metal chelation and antioxidant power of some of the Indian spices. Biofactors, 31(3-4), 219-227. https://doi.org/10.1002/biof.5520310309

Zimmermann, A., Hofer, S., Pendl, T., Kainz, K., Madeo, F., \& Carmona-Gutierrez, D. (2018). Yeast as a tool to identify anti-aging compounds. FEMS Yeast Research, 18(6), foy020. https://doi.org/10.1093/femsyr/foy020 